\title{
LINHA DIRETA COM QUEM?
}

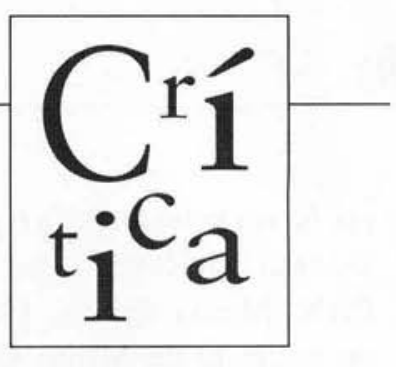

\section{Programa da Globo produz a estranha constatação de que a delação pode ser paradoxalmente uma atitude de engajamento cívico}

Conheço esse Linha direta de outras encarnações. Encarnações dele, não minhas (que com estas eu não brinco). Linha direta, na sua fase contemporânea, vai ao ar toda noite de quinta-feira, pela Globo, depois da novela. Baseado na reconstituição de casos policiais não-resolvidos, fisga o telespectador pela compaixão, pelo suspense e pelo ritmo de filme de ação. Ali, servida na tela, está a dor dos que perderam filhos ou irmãos assassinados. Ali, também, está a angústia que todos externam por não saber onde está o criminoso ou por não ter havido punição.

O programa costura documentário e montagens dramáticas. A parte, por assim dizer, documental da receita é com gente de verdade, que é entrevistada: testemunhas, parentes, amigos ou conhecidos daqueles que foram assassinados e daqueles que são acusados de homicídios. Há também advogados, promotores, juízes e demais autoridades, algumas francamente entusiasmadas com Linha direta. Quanto melhor essa "apuração jornalística" dos fatos, mais verossimilhança o conteúdo terá. A ação dramática é obtida pelo trabalho de atores em cena para pôr diante das câmeras as atrocidades narradas. Aí está o recurso mais grandiloqüente do programa. $\mathrm{O}$ andamento de todos os blocos é dado por essa técnica que, ao longo dos anos 90 , vem tomando cada vez mais espaço nos noticiários nobres, como o Jornal Nacional: a técnica de encenar os crimes para "dar a ver" o que, na vida real, nin- guém filmou. Graças a ela, as reportagens policiais do horário nobre ganharam muitas cores vibrantes, faces ameaçadoras e até fundo musical. Quase como um teleteatro ao ar livre, a reconstituição de chacinas e de emboscadas põe o telespectador face a face com a brutalidade; uma atrocidade que ficaria sensaborona ao ser apenas narrada por um locutor compungido, sem imagens; ganha contornos de um filme de ação ou, mais que isso, contornos de que todo aquele horror que se mostra se passou de fato diante das câmeras. O show do telejornalismo policial sobe na escala de impacto e de dramaticidade. Em Linha direta é assim o tempo todo. Funciona. Você mal sabe dizer onde termina o documentário e começa a dramatização; onde termina o mistério e começam as suposições; onde termina a matança e começa a justiça.

Mas não avancemos ainda. Eu ia dizendo que conheço esse Linha direta de outras encarnações e, de fato, se voltarmos uma década no tempo, nós o encontraremos numa outra fase. Era uma outra vida, um outro país. $\mathrm{O}$ apresentador não era o atual, Marcelo Rezende, mas aquele antigo repórter do Fantástico, Hélio Costa, que tinha virado políti-

\section{O AUTOR}

Eugênio Bucci

Jornalista, secretário editorial da Editora Abril. 
co, havia entrado para o partido do então presidente da República, Fernando Collor, o PRN. Meses depois, Costa seria candidato ao governo de Minas Gerais - e perderia. Já naquela época o programa tinha o mesmo receituário, fundindo jornalismo e teatro, mas, acima disso, era o pacto de delação o que lhe dava sua marca personalíssima.

Se Linha direta pudesse ser sintetizado numa única proposta de vínculo com o telespectador, essa proposta seria o pacto de delação.

Hélio Costa incentivava a platéia a mandar denúncias, a contar casos, a dizer se viu pelas redondezas alguns dos personagens que o programa mostrava. E garantia que a identidade do delator seria mantida em rigoroso sigilo. $\mathrm{Na}$ época, tive a impressão de que aquela fosse uma proposta imoral.

Atualmente é a mesma coisa. Continuo achando imoral esse tipo de interatividade acusatória. Agora não apenas o apresentador nos estimula a delatar, como o site da Rede Globo oferece o formulário. Você só tem de preencher. O seu anonimato é garantido. Vale a pena reproduzir aqui o texto do site da Globo (página de Linha direta):

"Se você tem alguma informação adicional sobre as histórias apresentadas ou alguma denúncia para fazer, escreva aqui. Sua identidade será mantida em absoluto sigilo.

Qual informação o(a) senhor(a) gostaria de passar?

Quem está envolvido? Como o(a) senhor(a) soube?

Quando? Tem alguém que o(a) senhor(a) conhece que nós poderíamos procurar ou investigar?

Gostaria de dar mais alguma informação ou pista?"

O que há quase dez anos mais me indignava no programa (publiquei um artigo a respeito na Folha de S. Paulo do dia 13 de maio de 1990) é o que ainda me chama a atenção. Imagino que o núcleo, a alma do programa se encontra precisamente nessa interatividade que promove a delação como forma de integração. Integra-se quem tem algo a delatar. Essa originalíssima interatividade compõe pelo país afora uma grande rede de vigilância, tão vasta quanto o índice do Ibope, que não é nada desprezível (é, ao contrário, bastante expressivo: em agosto, quando escrevo este artigo, o $\mathrm{Li}$ nha direta vem conseguindo semanalmente mais de 36 pontos). É a partir desse pacto que se organiza sua narrativa entre o documental e o dramatizado, entre o inquérito e a intriga, entre a delegacia e o circo. O desespero de quem não sabe por que ou por quem ou a mando de quem um parente foi fuzilado num beco escuro se converte em incentivo para que cada telespectador encontre ânimo de participar das investigações interrompidas.

\section{A SERVIÇO DA POLÍCIA}

A encarnação atual do programa vem sendo elogiada pelas autoridades porque, segundo atestam, ele estaria ajudando a solucionar os crimes que aborda. Uma reportagem da revista Veja, publicada em $1 .^{\circ}$ de setembro de 1999, página 149 (o título da matéria é Procura-se), dá conta de que criminosos ou suspeitos foragidos foram localizados e presos. "A produção do programa já contabiliza doze prisões realizadas graças a esse procedimento", lê-se na revista. Na mesma matéria, uma delegada dá seu depoimento sobre a importância da participação do telespectador em duas das capturas: "Se não fosse o programa, eles dificilmente teriam sido encontrados". Não apenas "encontrados", é bom frisar. Pelo menos um deles foi morto depois de ter seu rosto exibido na tela da Globo. Foi Marcos Capeta, autoproclamado "o novo 
Lampião", que, depois de virar personagem de uma das edições de Linha direta, acabou baleado e morto, segundo as informações, num tiroteio com policiais no interior baiano.

Pode-se mesmo, sem exageros, definir Linha direta como uma estratégia policial para arrebanhar colaboradores. Nessa perspectiva, ele é um programa a serviço da polícia - coisa que não faz dele pior ou melhor. Tomemos o fato como nada mais que um fato. E o fato é que Linha direta é uma campanha eficaz de delação.

A TV tem vocação para mobilizar seu público em causas que sejam de interesse dessas ou daquelas autoridades. A novela Explode coração serviu de campanha para que se localizassem crianças desaparecidas. Esporadicamente, Xuxa e Renato Aragão, entre outros, conclamam a classe média a doar alimentos e agasalhos para os que passam fome e frio. Há as campanhas de vacinação pela $\mathrm{TV}$, sempre bem-sucedidas. Os exemplos são vários e constantes; demonstram que a televisão tem a particular capacidade de cimentar cooperações entre o que pretende o poder público (ou simplesmente o poder, público ou não) e a ação voluntária (ou aparentemente voluntária) das massas. Isso, naturalmente, não significa que a televisão deva ser entendida como uma ferramenta de manipulação, um aparelho capaz de moldar comportamentos, nem significa que os telespectadores sejam passivos e cordeiros (é sempre trágico - e equivocado - pensar nesses termos). Isso apenas significa que a televisão tem servido de campo em que os sujeitos se reconhecem entre si como pertencentes a uma unidade (normalmente a pátria, uma torcida, um estilo um tanto etnográfico de ser "brasileiro") e que, diante dela, participar de campanhas mobilizadoras é um modo de constituir-se parte daquele todo. Do modo como foi historicamente construída no Brasil, a TV tornou-se o mais poderoso fator de integração nacional - e desempenhou sua missão por meio das redes comerciais abertas (a Globo na liderança). Quando esse grande modelo de TV se põe a serviço de um programa do tipo de $L i$ nha direta, temos a estranha constatação de que a delação pode ser paradoxalmente uma atitude de engajamento cívico.

\section{DEMOCRACIA OU TOTALITARISMO?}

Mas que tipo de unidade é essa que se baseia na acusação disseminada, anônima, em massa? Seria uma unidade típica do Estado democrático ou mais afinada com um Estado policial, totalitário? Em certos termos, a segunda alternativa é mais adequada. Um dos modos de distinguirmos o totalitarismo do autoritarismo é levarmos em conta o seguinte: no autoritarismo faz-se necessária a autoridade que a todos comande e oprima; no totalitarismo todos se convertem em agentes do poder. Por isso, no nazismo, pais denunciavam filhos subversivos e filhos acusavam pais suspeitos. Em regimes do tipo nazista ou fascista, a instituição do Estado policial sobrepuja a unidade familiar e a subordina à sua lógica totalitária. Todos, indistintamente, viram agentes do poder. Todos contra todos. Não pretendo aqui pensar que Linha direta seja um programa nazista, o que ele efetivamente não é, mas apenas discuti-lo sob o aspecto de que ele se vale de um tipo de vínculo com o público que faz lembrar, ainda que de modo longínquo e indireto, alguns traços do totalitarismo.

Raciocinando no limite, teríamos: se o Linha direta fosse um programa diário, com $60 \%$ de audiência, o Brasil seria um país de delatores anônimos permanentemente mobili- 
zados. Seríamos um país de agentes policiais. $\mathrm{O}$ ponto mais grave, contudo, talvez esteja na garantia do anonimato. Pense comigo: o que pode fazer alguém que foi injustamente acusado e nem ficou sabendo disso? E alguém que por isso foi detido, investigado e interrogado? Pode ele se queixar contra o autor da denúncia? Como, se esse autor é mantido em sigilo? $\mathrm{O}$ que impede alguém de caluniar alguém se, no fim, não será responsabilizado pela acusação que enviou para o site da Globo?

A emissora, é claro, não dará curso a todo tipo de delírio que chegue até ela. Pode alegar em sua defesa que faz uma filtragem das delações. Mas, assim mesmo, será correto que ela incentive essa prática entre seus telespectadores, muitos deles desinformados sobre os direitos da cidadania e sobre as normas da boa convivência social?

Todos sabemos que, em certas áreas do Brasil, o anonimato muitas vezes é a única forma de garantir o acesso de um cidadão à polícia, pois, se sua identidade for revelada, ele estará exposto a vinganças e retaliações. Mas para esses casos a polícia é a instituição preparada, seus funcionários são formados e treinados para lidar com esses dados dentro da normalidade democrática. (Ao menos em tese, para efeito da nossa

Resumo: Eugênio Bucci analisa Linha direta, uma alternativa mais elaborada da Rede Globo a programas do estilo. O autor chama a atenção para o jogo dramático de encenação, luzes e sons, que leva o espectador à interação com o que está sendo mostrado (a reconstituição de crimes praticados e sem solução até o momento), na tentativa de conduzi-lo ao ato essencial - a delação - para o qual ele tem à disposição meios de comunicação e garantia de anonimato. Ele define o programa como uma estratégia policial para arrebanhar colaboradores, politicamente uma estratégia autoritária que busca a conversão de todos em agentes do poder.

Palavras-chave: Linha Direta, Rede Globo, delação, programa policial, jornalismo, autoritarismo argumentação.) Por isso, todos sabemos também que esse tipo de expediente deve ser mantido sob controle - jamais deve ser massificado. Assim, por maior que seja o número de suspeitos localizados por programas como Linha direta, é sempre bom refletir se tal fim justifica o meio.

A emissora pode argumentar que não põe no ar qualquer caso policial, mas apenas aqueles em que os suspeitos são francamente culpados e que a adesão de mais agentes de vigilância só irá contribuir. Mesmo assim, não é o que diz o site da emissora. Ali, qualquer denúncia é solicitada e bem-vinda. Portanto, é pertinente um debate ético sobre a validade de alguns recursos utilizados por Linha direta.

Eu assisti a vários programas da nova encarnação. Eles são cada vez mais bem armados, a edição é feérica, magnetiza a audiência, e a narrativa é bastante convincente. Tecnicamente (se é que é possível abstrair a técnica de todo o resto), temos uma televisão de boa qualidade. Tudo isso, toda a técnica e toda a qualidade estão a serviço de arregimentar delatores. O show serve para mobilizar os delatores e os delatores servem para reanimar o show. De minha parte, pelo menos até agora, prefiro sonhar com um país onde esse tipo de coisa não acontecesse mais. Nem nesta nem nas outras encarnações.

Abstract: Eugênio Bucci analyzes Linha Direta (Direct Line), a more elaborate Rede Globo alternative to this type of program. The author calls one's attention to the dramatic staging, lighting and sound game that leads the viewer to interaction with what is being presented (the reconstitution of an unsolved crime), in an attempt to lead one to the essential act - finger-pointing. To do this one has the means of communication available and anonymity insured. He defines the program as a police strategy to gather collaborators, a politically authoritarian strategy that aims at converting everyone into an agent of power.

Key words: Linha Direta, Rede Globo, denunciation, police program, journalism, authoritarianism 